progress of the llangerous alteration already begun; and we can thus understand how depletion or venesection may convert a threatening of apoplexy into a real attack, and how it is warded off by quinine and tonics. Of course, under these circumstances, it is of the utmost importance that no unusual strain shall be laid upon the weakened capillaries; and both bodily and mental excrtions must be avoided.

It is an interesting question to consider how far vessels which have become degenerate may recover themselves. Wo cannot answer this satisfactorily; but we know that if they do, it must be through the medium of the systemic powers, and that these eannot act with effect as long as the individual is in a depressed condition. Supposing, again, that we have evi dence of cerebral hæmorrhage having taken place, how is the blood to be taken up again? It is clear from the nature of things that it will not return into the vessels again by the same route it left them. It can only be taken up then by the ordinary means that are adopted by nature elsewhere. A clot in the brain is analogous to ecchymosis in the skin, and follows much the same laws. A bruise is readily recovered from in youth, but not so in old age: and, as we often have occasion to remark, the phthisical and the aged have far more extensive ecchymosis from a given injury than the robust and strong. The extent of the effusion evidently depends on more extensive rupture of vessels (most probably caused by degen eration) in the one than in the other. An apoplectic clot then must be taken up by the surrounding healthy brain; but it must be borno in mind that the surrounding brain is probably not healthy-its vessels are degenerate in the same manner as those which gave way, and are themselves obroxious to be completely closed. The circulation in them, necessarily lan. guid from their diminished calibre, may now be arrested altogether by the squeezing effect of the effused blood. This would probably occur constantly, if the heart were not able to propel the blood through them in spite of the obstacle. But when the heart is enfeebled at the same time that the vessels are compressed, however slightly, circulation through the parts surrounding the clot ceases, and the brain softens and dies. Anything, therefore, that depresses the system and diminishes the power of the heart, has in reality a direct tendency to produce softening around the clot; nor would it be difficult to adduce cases from Dr. Abercrombie's works, and those of other systematic writers, in which softening round the clot has been brought on by the means used with the intention of preventing such a catastrophe. (See a case given in Dr. Watson's Practice of Medicine, vol. i, p. 511 ; third edition.)

The effect of mercury, which is very commonly given with a view to "stimulate the absorbents", is generally prejudicial in cases of cerebral hæmorrhage. That it should ever be admin istered by any one who had read the following observation, is almost incredible. Dr. Porter remarks:-" Almust all the aged people treated with mercury for syphilis have, according to my observation, lied shortly after of hæmoptysis or apoplexy. Nor are such casualties confined to the aged; for I have seen several instances of young persons under similar circumstances being seized with hæmoptysis, and dying rapidly of consump tion." (Ranking's Abstract, vol. v, p. 66.)

Many practitioners do not push calomel far in cases of apoplexy, and use it in simply aperient or alterative doses; but even this is prejudicial, unless there is some special reason for acting on the bowels, and the patient is buoyed up by tonics and generous diet. Few can take, even when in health, a dose of ealomel or blue pill without feeling low and good for nothing the next day. The same occurs in the sick; but as they are for the most part in the recumbent posture, it is not equally noticed. Surely, if in the main it is undesirable to depress a patient with apoplexy by such powerful means as bleeding, it ought to be considered undesirable to depress him by more gentle plans. It would sound absurd for a thief to say he had not abstracted a sovereign, because he had only taken it by sixpence at a time. It is true, that a pilferer may abstract many a shilling without being found out, who would be detected at once if he took a five-pound note; and so many a doctor abstracts by driblets an amount of strength which he dare not take at once. The robbery would be too patent both to him. self and the patient.

We consider then that a frequent use of mercury is a depressing agent; and that its chief value is when from a combination of favourable circumstances, it promotes the appetite and digestion. Purgatives are obnoxious to the same remarks. Low diet, or an abstinence from a moderate amount of accustomed stimulants, is equally to be deprecated as incompatible with a sustentation of the natural vital or restorative powers.
In all things, the motto of the medicus should be:-" Be nature's handmaid-not her tyrant."

P.S.-I may state that the foregoing remarks upon the capillaries are, I believe, original; and that I hope shortly to give to the profession a history of "atheroma in arteries, and the important bearings it has upon pathology and practice."

\section{FURTIER REMARKS ON THE ANALYSIS OF UREA IN URINE FOR CLINICAL PURPOSES.}

\section{By J. L. W. Thudichum, M.D.}

Is a former article on this subject, I endeavoured to define the principles upon which the analysis of urea in urine for clinical purposes was to be based, in order to insure its utility for pathology and patients. I also compared the usefulness to the practitioner of the proceedings for analysing urea by Liebig and Davy. I described some precautions which I had taken for the purpose of making Davy's method more accurate; and then contrasted with these principles the proceeding of $\mathrm{Dr}$. Handfield Jones for analysing urea in urine. It was singular that Dr. Jones should have made use of a method, and termed it a modification of that proposed by Dr. Davy, when the latter author had especially declared this proceeding (upon which he only calculates as the result of accident, not of design), to violate the integrity of his analysis.

From a knowledge, literary and experimental, of the quantity of urea discharged in given times by healtby individuals and by individuals labouring under fever, I came to the conclusion that the quantities of urea alleged to have been discharged by Dr. H. Jones's patients were far below the normal quantities in health, and therefore were opposed to all other analyses on this point, which coincided in finding a larger quantity of urea discharged by fever patients than by healthy persons during equal times. This was ascertained by a comparison of figures, and accounted for by the analytical proceeding. If any reason for condemning the modification was wanted, it has been supplied by the five careful experiments detailed by Dr. Jones in his Supplement to Observations on Elimination in Fever (BRITISH MEDICAL JoURNAL, Oct. 3rd, 1857, p. 830.)

In the first of these experiments, one drachm of a certain urine, with diluted liquor sodæ chlorinatæ, yielded $1 \cdot 29$ cubic inch of nitrogen. (I suppose the dilution was effected with an equal bulk of water, as in Dr. Jones's first experiments; but he has not stated the proportions in which liquor and water were mixed.) One drachm, with 1.6 cubic inch of mercury (and liquor sodæ chlorinatæ, I suppose, so as to imitate Dr. Davy's proceeding, from which I further conclude that the liquor was undiluted) yielded 1.52 cubic inch of nitroger,; one drachm, with undiluted liquor sodæ chlorinatæ, yielded $2 \cdot 1$ cubic inches.

If any one of these three results, or all three, are quite unimpeachable, the following conclusion becomes unavoidable. That Dr. Jones's original analysis, with his modification, yielded little more than one-half of the quantity of urea that can be ascertained, by liquor sodæ chlorinatæ, to be present in a drachm of urine. I say little more than half ; for 1.2! is little more than the half of $2 \cdot 1$. Dr. Jones therefore atfords experimental proof, that I am quite correct in asserting (p. 789 of this JOURNAL) that in his analysis the loss of nitro' almost to one-half of the nitrogen actualliy contained." Dr. Jones acknowledges having arrived at a similar conclusion, for he says (Supplement, p. 8:30): "The first experiment shows that with diluted liquor sodæ chlnrinatie a less amount of gas is evolved than in the other cases; a like result was obtained in some other trials."

Dr. Jones does not rest satisfied with this result of his analysis; and having accidentally found more nitrogen by an experiment without mercury than was obtained from an equa quantity of urine with the use of mercury, he has performed more analyses, the results of which are intended to show, " that when undiluted liquor sodæ chlorinatæ alone is employed, the amount of nitrogen disengared is above, or very nearly equal to that which is obtained, when mercury and liquor soda chlorinate are used in Dr. Davy's original way." This resul would drive us to the conclusion (provided again that the experiments were unimpeachable), that Dr. Davy's method is so bad an analytical proceeding, as to cause large quantities of nitrogen to be lost thereby. A comparison of the figures in the following table will make the apparent loss conspicuous. 
Cubic inclies of nitrogen obtained by Dr. Jones from one ounce of urine.

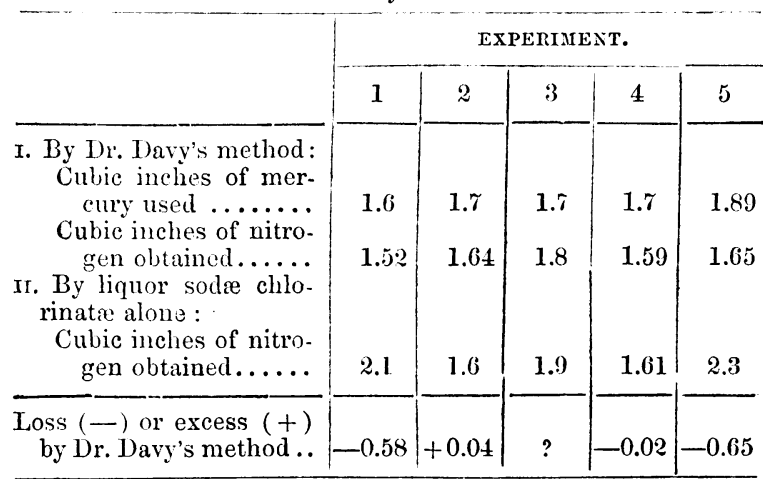

As, in the third experiment, the amount of mercury used was too small, it must be condemned. In the second experiment, more nitrogen is obtained by Dr. Davy's method than by the modification. There remain, therefore, three experiments, in which more nitrogen was found by the modification than by Dr. Davy's original way.

Dr. Jones does not account for such an extraordinary result. If a drachm of urine contains a sufficient amount of nitrogen, to yield, after complete decomposition by liquor sodæ chlorinatæ, $2 \cdot 1$ cubic inches of the gas, this amount of gas must necessarily be obtained from another drachm of the same urine, if liquor sodæ chlorinatæ and urine are brought together over mercury. Common sense demands this result, and the necessity of this result constitutes the value of Dr. Davy's proceeding. How then is it possible to find more nitrogen by another proceeding, which, under all circumstances, must be accompanied by a loss of mixture of liquor and urine, and of some gas contained therein? I may be permitted to put my construction upon these strange but necessary facts.

In none of his analyses has Dr. Jones proved that the whole amount of urea was actually decomposed. The omission of this caution (which consists in the addition to the mixture in the tube of a new quantity of liquor sodæ chlorinatæ, to see whether any reaction does yet take place, or not, in which latter case the decomposition may be considered to be perfect) greatly diminishes the value of these proceedings. Dr. Jones appears satisfied in having taken more of the decomposing liquor than Dr. Davy prescribes to be taken. This precaution in no case amounts to evidence that enough of the liquor has been used. Evidence is only afforded by the absence of any reaction whatsoever on the addition to the mixture of a new quantity of liquor. This evidence is absolutely necessary for any demonstration of quantity. If a hundred drachms of liquor sodæ chlorinatæ for one drachm of urine had been used, this test would still be necessary for demonstration. The correctness of this proposition will be admitted by everybody.

In the analyses performed by Dr. Jones without mercury, the drachm of urine was mixed with so much more liquor as corresponded to the bulk of the mercury used in the parallel series performed with mercury; namely, to the rough average of $\mathbf{1 . 7}$ cubic inch. The urine in the experiments without mercury was therefore mixed with a very much larger proportion of the decomposing liquor. That amount of mixture which eventually was driven out had time to evolve a certain portion of its nitrogen before it left the tube; the rest of the urea was mixed with a larger proportion of liquor than the urea in the tubes with mercury; it was, therefore, more completely decomposed, and yielded more gas, than the urea in the tubes with mercury, which was not entirely decomposed. For, if it had been entirely decomposed, nitrogen to the same amount at least as in the experiments without mercury, must, by natural necessity, by the laws of matter, by all conclusions of reason and common sense, have been obtained.

I did not enter upon a criticism of Dr. Jones's determinations of uric acid. But as Dr. Jones challenges proof that his determinations of uric acid are not accurate, I must well consent to give the proof.

CASE I. Uric acid on Oct. 10th, $23 \cdot 76$ grains (in 24 hours). Ditto Oct. 23rd, $4 \cdot 20$ grains. Much uric acid was deposited. This deposit should have been added to the $4 \cdot 20$ grains weighed, when the true amount of uric acid from 24 hours would have been apparent. As the observation stands, it is clearly inaccurate.
Uric acid on Nov. 14th. "A trace. There was besides a copious precipitate of uric acid, which fell down spontaneously, and could not be estimated." Dr. Jones had clearly the idea that a deposit of uric acid had no connection with the uric acid in solution, and must not be added to it. This error is shared by many who assume a deposit to be a sign of excess. The observation on Oct. 23rd may be turned to use, as demonstrating that a deposit is a part of the usual quantity of uric acid in the urine.

Passing Case II, which Dr. Jones himself questions at the end of Case III, we find the proceeding regarding uric acid repeated in Case III.

December 9th. Urine of twenty-four hours had a whity deposit, and yielded a total of 5.88 grains of uric acid. In the deposit were masses of uric acid, which were not comprised in the quantity given. If they had been comprised, and had been recovered from the granular and homogeneous casts, from the renal epithelium, and blood, I am quite sure Dr. Jones would have stated so, and how it had been accomplished. The determination in this case also is of no use, because a part of the acid was lost undetermined. The same occurs on December 19th, in Case IV. Cases v, vI, and vII, offer other features, which interfere with the correctness of the analyses for uric acid. The reader, on comparing the quantities of uric acid found in the urine of the respective days, will find that they stand in an inverse proportion to the quantities of urine.

$$
\begin{aligned}
& \text { Date. Urine (ounces). Uric acid (grains) } \\
& \text { Case Iv.-Nov. 5th } \ldots \ldots . \quad 12 \quad \ldots \ldots . \quad 1.56
\end{aligned}
$$

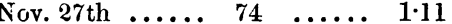

$$
\begin{aligned}
& " \quad \text { Dec. 19th ...... } 66 \text {..... } 3.96 \text {, and } \\
& \text { a good deal of spontaneous deposit. } \\
& \text { Case v.-Dec. 2nd } \ldots . . . \quad 51 \quad \ldots . .61 .02 \\
& \text { " Jan. 8th } \ldots . . .82 \quad \ldots 2 \text {. } 82 \text { a trace }
\end{aligned}
$$

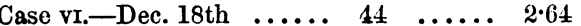

$$
\begin{aligned}
& \text { Jan. 5th } \ldots \ldots .79 \quad 79 \quad \ldots \text { a trace } \\
& \text { Case vir.-July 9th } \ldots \ldots . .38 \text {..... }
\end{aligned}
$$

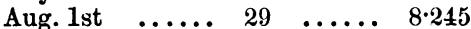

The largest quantities of urine in twenty-four hours -82 and $79 \mathrm{oz}$-yielded only traces of uric acid: the smaller quantities. yielded more uric acid, but still very small amounts. It has occurred to Dr. Jones, what occurs to beginners, and what may be learned from books; namely, that dilute urine does not give up its uric acid in a solid state, when treated with acids for the purpose. Dr. Jones forgot, or omitted, to concentrate the dilute urine before adding the acid for the precipitation of uric acid; and thus he only obtained traces where he would probably have found large quantities if the proper mode of analysing had been had recourse to. It will thus be apparent that it was upon the reasoning from experiment and the knowledge of literature that I questioned Dr. Jones's determination of uric acid.

But what am I to say of the assertion, that no boiling is necessary with the soda solution used for determining the amount of free acid in the urine, to obtain a neutral solution? Chemists are in the habit of using a solution of caustic soda, in order to avoid the difficulty of the free carbonic acid, which requires protracted boiling in order to be entirely removed. They direct that even the fluids treated with this caustic soda should be heated, in order to remove the trace of carbonic acid which adheres to this solution with so much pertinacity: and, as I suppose that Dr. Jones ascertains neutrality or acidity of urine by means of litmus papers, it is difficult to understand how his litmus can indicate neutrality as long as any free carbonic acid is contained in the solution, which, in the experiments of other chemists, has a faint though decidedly acid reaction. Let me refer Dr. Jones to authorities in alkalimetrical analyses, and quote Kersting's article in the Annalen $d e r$ Chem. und Pharm., Bd. xciv, p. 112, where the behaviour of carbonic acid and litmus is fully described; or to Mohr's Lehrbuch der Chem. Analyt. Titrirmethode, p. 102, and Supplement to p. 102 at p. 350.

Dr. Jones again asserts that more gas is generated in the upper part of the tube than in the lower part. He only meets my objection with a denial. I will, therefore, explain his erroneous impression. Suppose the column of fluid in the tube to be divided into horizontal layers, each of the thickness of the diameter of one of the bubbles of nitrogen; and suppose an equal reaction to take place in all parts of the tube; that is to say, equal numbers of equal bubbles of nitrogen to be evolved by all layers in equal times, and to rise at an equal rate (which they do not, rising quicker in the higher than in the lower strata), then the following condition would take place: the bubbles 
from the lowest stratum would at the second stratum be joined by the bubbles formed here, and at the third stratum by a third set of bubbles, and at the hundredth stratum there would be a set of bubbles together generated in a hundred strata. Thus, in the hundredth stratum, there would be a hundred times as many bubbles as in the lowest stratum; and, if the process went on uninterruptedly, these relative numbers would be constantly present. The phenomenon is best demonstrated on champagne; and the regular followers of science could not resist even my explanation derived from so plausible a rnaterial. Now, if Dr. Jones will try the experiment upon a bottle, the last glass will quite convince him of the correctness of my explanation. It requires repeated examination to find that the many bubbles in the upper strata are not all generated there, but have only risen to that position from lower spheres. Dr. Jones is evidently under a misconception when he assumes the drachm of urine not to be thoroughly mixed; for, on the addition of liquor to the drachm of urine, the liquor must sink to the bottom, as being of the highest specific gravity ;* and the urine must rise, and permit all subsequent portions of liquor to pass through its substance. And then the tube is inverted, and, should any urine be left unmixed, it would have to go to the top again; hereby, and by the rapid evolution of gas, the fluid is brought into such a commotion that it must be most intimately mixed. Indeed, if neither the different specific gravities nor the commotion caused by the gas did effect an intimate mixture, the mere act of pouring ten, or twenty, or more parts of the liquor down a long tube, to one part of urine, would speedily effect a mixture; and, if that mixture was not effected in the manner I have described, it could not be effected at all, because, if the urine could ever be at the top of a column of the liquor, it must remain there, in virtue of its lower specific gravity, and could not on any account descend in the manner described by Dr. Jones.

I have made only a limited number of analyses by Dr. Davy's method, but never found any inconvenience from the mercury, such as Dr. Jones asserts that he has met with. A friend of mine, who has made many hundred analyses in this way, never observed the mercury being driven violently out and scattered about, and cannot account for this singular mishap to Dr. Jones, which caused him to adopt his first modification.

I hope Dr. Jones will continue his researches with improved methods. He has rare opportunities, and, being a pathologist, might turn them to good account. The fact of such a man applying himself to chemical analysis is an illustration of the turn which medicine is taking. We have had a great deal of pure chemistry: what we want now is chemistry applied. Applied to medicine, chemistry can only be by the profession itself, otherwise there will be no end of conflicts. If, then, the older members of the profession do not find application to quantitative analysis quite easy, they must not be astonished at it, for it took their junior colleagues years of practical study in the laboratory, and not a little reading and headwork, to attain the little which they can call their own. That ground it is their duty carefully to weed and cultivate, in order to come up to the expectations of those well versed in science, who assert that, in a short time, no physician would be able to give an opinion unless he be a microscopist and a chemist.

\section{CASE OF FEMORAL HERNIA.}

By Edwari) A. Brown, Esq., Surgeon, Eastwood.

Aт 12 o'clock on the night of Friday, June 27 th, I was sum moned to attend Mrs. G., a near neighbour residing at Eastwood, suffering from strangulated femoral hernia, brought on by sudden and unusual exertion. The symptoms were well marked and severe. The pulse was irritable, about 90 . There were anxiety of countenance, vomiting of bile and mucus, and distressing pain referred over the entire abdomen. She was placed in the usual position, with the thigh of the affected side rolled inwards towards the opposite one; and the taxis was applied in the direction downwards, backwards, and upwards, for twenty minutes, ineffectually. An ordinary stimulating enema was then ordered; effervescing medicine, with hydrocyanic acid and an opiate, were prescribed; and the case was left till the following morning.

* 1.034, according to the "Dublin Pharmacopœia". The "London Pharmacopœia" gives no determined specific gravity of its preparation. The liquor, obtained from Mr. Morson, of Southampton Row, I found to have the specitic gravity of 1.043 .
June 28th, 8 A.r. There was no improvement, though the symptoms were somewhat masked by the anodyne. There had been no evacuation by the bowels. She had obstinate vomiting, increasing pain, anxious and distressed countenance. The taxis was again employed, with the use of warm bath, unsuccessfully, for twenty-five minutes, this being as long as the tenderness of the sac would admit of. Continue medicines.

2 P.м. Reduction was again ineffectually attempted.

8 P.M. There was no improvement; the symptoms were becoming aggravated. The taxis was used half an hour, under the influence of chloroform, unsuccessfully. The patient was left for the night.

June 29th, 8 A.Mr. There was constant stercoraceous vomiting, excessive pain and dragging all over the abdomen, eructation, hiccough, and tympanitis. The bowels had not acted; the pulse was hard, wiry, 140. It being now high time to afford relief if possible, the operation was proposed, and acceded to.

There being only an old woman and myself present, the inconvenience of giving chloroform and operating can readily be conceived, especially in a cramped up chamber, and with bad light. The patient, moreover, being naturally weakly, and further reduced by suffering, it was not wise to overdo the administration of chloroform; the consequence was, that she occasionally came to, which delayed the steps of the operation. Making the usual incisions, and dividing the several coverings down to the sac, I proceeded at once to open it, numerous adhesions around quite preventing it from being returned. I found the neck tightly embraced; the bowel was of a chocolate colour, and the vessels circulating on its surface were greatly congested. On dividing upwards, and very slightly inwards, a portion of Poupart's ligament, the return of the hernia could not be effected; and the stricture was evidently caused by Gimbernat's ligament. The bowel was also punctured with a grooved needle, and the flatus expelled to afford relief, but without effect. On carefully exploring the opening with the finger-end, distinct pulsation could be felt, from an irregular distribution of the obturatrix artery surrounding the inner part of the neck of the sac; and, being indisposed to risk its division, having oiled the forefinger, I gradually dilated the opening, and was pleased to find the method quite successful, the bowel being returned without much difficulty.

I ordered an enema of warm gruel, a dose of castor oil, and a mild mercurial purge. The bowels were freely acted on. Her symptoms were materially relieved, though peritonitis supervened: this, however, fortunately gave way readily to treatment, and everything progressed to a favourable issue.

November 3rd. Not the slightest inconvenience has arisen since the operation; and she speaks of the affected side being stronger and more comfortable than the opposite one. I have not the least doubt of the obliteration of the weakened aperture. She has for a corrsiderable time been taking her ordinary food, and follows her ordinary avocation, being quite well. One of Huxley's elastic abdominal belts, with air-pad, has been supplied, and affords great support and comfort.

REMARKS. The process of mechanical dilatation acted in this case most favourably.

1. The risk of wounding the obturatrix artery was removed.

2. The part itself was not so weakened subsequently as by division with the knife.

3. Although, if too roughly handled, the gut might be bruised, in the absence of this, inflammatory action may take place around the neck of the sac, causing effusion of lymph and a repair of the otherwise weak points of the parietes. In the present case, I fully believe this has actually occurred.

\section{THE TREATMENT OF ACUTE RHEUMATISM.}

By Henry William Fuller, M.D.Cantab, F.R.C.P., Physician to St. George's Hospital.

Dr. Inman's article on the treatment of acute rheumatism, inserted in our Jounnal on October 24th, demands a passing notice. Its quotations are incorrect, its statements of a strangely perplexing nature, and its conclusions at variance with the result of observations in London, Liverpool, and elsewhere.

And, firstly, as to Dr. Inman's quotations, or rather the statements and opinions he puts into my mouth. "Dr. Fuller," he says, "gives as the average duration of his cases five weeks." How far this quotation is consistent with accuracy may be 